\title{
Exchange bias and the origin of magnetism in Mn-doped $\mathrm{ZnO}$ tetrapods
}

\author{
R. K. Zheng, H. Liu, and X. X. Zhang ${ }^{\text {a) }}$ \\ Department of Physics and Institute of Nano Science and Technology, Hong Kong University of Science \\ and Technology, Clearwater Bay, Hong Kong \\ V. A. L. Roy \\ Istituto per lo Studio dei Materiali Nanostrutturati, C.N.R., Via Gobetti 101, 40129 Bologna, Italy
}

A. B. Djurišić

Department of Physics, University of Hong Kong, Pokfulam Road, Hong Kong

(Received 23 March 2004; accepted 29 July 2004)

\begin{abstract}
Wurtzite-type $\mathrm{ZnO}$ tetrapod nanostructures were prepared by evaporating $\mathrm{Zn}$ metal under humid argon flow. After the fabrication, Mn was doped into $\mathrm{ZnO}$ nanostructures by diffusion at $600{ }^{\circ} \mathrm{C}$. The average concentration of $\mathrm{Mn}$ was determined to be $8.4 \mathrm{~mol} \%$ by $\mathrm{x}$-ray fluorescence. X-ray diffraction patterns obtained from the doped and undoped samples are almost the same. High-resolution transmission electron microscopy observations reveal the existence of surface layers. Magnetic measurements show that the sample has a very large coercivity $H_{C}=5500 \mathrm{Oe}$ at $5.5 \mathrm{~K}$ and a Curie temperature $T_{C}=43 \mathrm{~K}$, which may suggest that ferrimagnetic ( $\left.\mathrm{Zn}, \mathrm{Mn}\right) \mathrm{Mn}_{2} \mathrm{O}_{4}$ exists at the surface. Exchange bias is clearly observed below $22 \mathrm{~K}$. Exchange bias is attributed to the exchange interaction between ferrimagnetic ( $\mathrm{Zn}, \mathrm{Mn}) \mathrm{Mn}_{2} \mathrm{O}_{4}$ and spin-glass-like (or antiferromagnetic) phase in manganese oxides. (C) 2004 American Institute of Physics.
\end{abstract}

[DOI: $10.1063 / 1.1795366]$

Magnetic semiconductors have been intensively studied recently due to the application in spintronics, which offers opportunities for the next generation of devices by combining standard microelectronics/nanoelectronics and spindependent effect. ${ }^{1}$ In order to achieve large spin polarization in semiconductor, the Zeeman splitting of the conduction band (valence) must be greater than the Fermi energy of electrons (holes). ${ }^{1}$ Therefore, the ferromagnetic semiconductors with Curie temperatures, $T_{C}$, above room temperature are desired. Since theoretical calculations predicted $\mathrm{Mn}$ doped $\mathrm{ZnO}$ can be ferromagnetic even above room-temperature, ${ }^{2}$ much effort had been done. ${ }^{3-19}$ Theoretical calculations predict that $\mathrm{Mn}$ doped $p$ type $\mathrm{ZnO}$ should be ferromagnetic at room temperature. ${ }^{2,20,21}$ However, in the absence of $p$-type doping, $\mathrm{Mn}$ doped $\mathrm{ZnO}$ would exhibit antiferromagnetic properties. ${ }^{20,21}$ Experimental results on $\mathrm{Mn}$ doped $\mathrm{ZnO}$ are quite contradictory to each other. Paramagnetic properties were reported for $\mathrm{Zn}_{0.93} \mathrm{Mn}_{0.07} \mathrm{O}$ films prepared by magnetron sputtering. ${ }^{11}$ Antiferromagnetic behavior was observed in $\mathrm{Zn}_{0.64} \mathrm{Mn}_{0.36} \mathrm{O}$ films prepared by pulsed laser deposition ${ }^{5}$ and polycrystalline $\mathrm{ZnO}: \mathrm{Mn}$ powder samples. ${ }^{12}$ However, ferromagnetism was reported in $\mathrm{Mn}$ implanted $\mathrm{ZnO}: \mathrm{Sn}$ single crystals $\left(T_{C}=250 \mathrm{~K}\right),{ }^{10} \mathrm{Zn}_{1-x} \mathrm{Mn}_{x} \mathrm{O}$ films $\left(T_{C}=30\right.$ and $45 \mathrm{~K}$ for $x=0.1$ and 0.3 , respectively) prepared by laser molecular beam epitaxy, ${ }^{8}$ and $\mathrm{Zn}_{1-x} \mathrm{Mn}_{x} \mathrm{O}$ nanowires $\left(T_{C}=37 \mathrm{~K}\right.$ for $\left.x=0.13\right)$ prepared by vapor phase growth. ${ }^{17}$

Besides the ferromagnetic and antiferromagnetic orders due to the exchange interaction between Mn cations that substitute $\mathrm{Zn}$ cations, manganese oxides also have strong magnetism: $\mathrm{MnO}$ and $\mathrm{MnO}_{2}$ are antiferromagnetic, $\mathrm{Mn}_{3} \mathrm{O}_{4}$ and $(\mathrm{Zn}, \mathrm{Mn}) \mathrm{Mn}_{2} \mathrm{O}_{4}$ are ferrimagnetic. It is therefore crucial to clarify where the magnetism comes from. In this letter, we

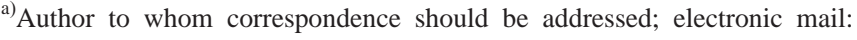
phxxz@ust.hk
}

report the structural and magnetic studies on the Mn doped $\mathrm{ZnO}$ tetrapod nanostructures. A large coercivity $H_{C}$ $=9200 \mathrm{Oe}$ and an exchange bias field $H_{E}=300$ Oe were observed at $2 \mathrm{~K}$ and surface layers was found to cover on the tetrapods. We attribute exchange bias to the exchange interaction between ferrimagnetic $(\mathrm{Zn}, \mathrm{Mn}) \mathrm{Mn}_{2} \mathrm{O}_{4}$ and spinglass-like (or antiferromagnetic) phase in manganese oxides. $\mathrm{ZnO}$ tetrapod nanostructures were fabricated as follows. ${ }^{22} \mathrm{Zn}$ powder was evaporated in a quartz tube at $950{ }^{\circ} \mathrm{C}$ under the Ar flow of $0.71 / \mathrm{min}$, which passed through water before being introduced into the tube furnace. $^{22}$ Diffusion doping was performed by placing $0.654 \mathrm{~g}$ of $\mathrm{ZnO}$ tetrapods and $0.054 \mathrm{~g}$ of $\mathrm{Mn}$ in the tube furnace at $600{ }^{\circ} \mathrm{C}$. The quartz process tube was then connected to a vacuum pump and diffusion was performed for 30 min. ${ }^{19}$ The $\mathrm{Mn}$ content was determined using x-ray fluorescence spectrometer (XRF). The structure of the sample was investigated by $\mathrm{x}$-ray diffraction (XRD) and high-resolution transmission electron microscopy (HRTEM). Magnetic measurements were performed using superconducting quantum interference device (SQUID) magnetometer.

The typical XRD spectra for undoped $\mathrm{ZnO}$ nanostructures are shown in Fig. 1, which indicates only a wurtzitetype structure with the lattice parameters, $a=0.325$ and $c$ $=0.521 \mathrm{~nm}$. Although the XRF results reveal that the Mn content of the doped sample is $8.4 \mathrm{~mol} \%$, the peaks of the XRD spectrum of the doped sample are at the same positions as the corresponding ones of the undoped and no additional peaks can be clearly seen, as shown in Fig. 1. If significant Zn cations were substituted with larger Mn cations, the peaks should shift to lower angle due to the enlargement of lattice parameters according to the previous results. ${ }^{4,8,14,17}$ For diffusion doping method, the Mn concentration should decrease gradually from surfaces to insides of the $\mathrm{ZnO}$ nanostructures. The Mn cations may therefore exist mainly near the surfaces, 




FIG. 1. XRD spectra show that both the undoped and $\mathrm{Mn}$ doped $\mathrm{ZnO}$ tetrapod nanostructures are wurtzite type. The XRD peaks of the doped sample are identical to those of the undoped.

and the inside $\mathrm{ZnO}$ remain nearly unchanged. If the XRD patterns are dominated by the inside $\mathrm{ZnO}$, the peaks may be at the same positions as those of the undoped sample.

If the Mn cations mainly exist near the surfaces for a dopant up to $8.4 \mathrm{~mol} \%$, manganese oxides could form, which may dominate the magnetic behaviors of the doped samples. To verify this point, HRTEM studies were performed.

Figure 2 is a HRTEM image of a Mn doped $\mathrm{ZnO}$ tetrapod. The existence of a surface layer is evident. The fast Fourier transform (FFT) diffractogram is depicted in the left inset. This FFT diffractogram is indexed to be [100] oriented wurtzite-type $\mathrm{ZnO}$, which is consistent to the XRD results. This FFT diffractogram also reveals that the pod grows along [001] direction.

Zero-field cooled (ZFC) and field cooled (FC) magnetizations of the $\mathrm{Mn}$ doped $\mathrm{ZnO}$ nanostructures were measured in a 100 Oe field. As shown in Fig. $3, T_{C}=43 \mathrm{~K}$ can be clearly seen, which is consistent with Curie temperature of ferrimagnetic $\mathrm{Mn}_{3} \mathrm{O}_{4}{ }^{23,24}$ Above $1443 \mathrm{~K}, \mathrm{Mn}_{3} \mathrm{O}_{4}$ is cubic spinel, whereas it becomes tetragonal distorted spinel below $1443 \mathrm{~K}$ in which $\mathrm{Mn}^{2+}$ ions occupy the tetragonal A sites and $\mathrm{Mn}^{3+}$ ions occupy the octagonal B sites. ${ }^{24}$ The paramagnetic Curie temperature, $T_{\Theta}$, of the sample is about $\sim 517 \mathrm{~K}$, which is in accordance with the previously reported values. ${ }^{24}$ Since secondary ion mass spectrometer (SIMS) measurement indicates the existence of $\mathrm{Zn}^{2+}$ at the surface and $(\mathrm{Zn}, \mathrm{Mn}) \mathrm{Mn}_{2} \mathrm{O}_{4}$ has the similar properties to $\mathrm{Mn}_{3} \mathrm{O}_{4}$,

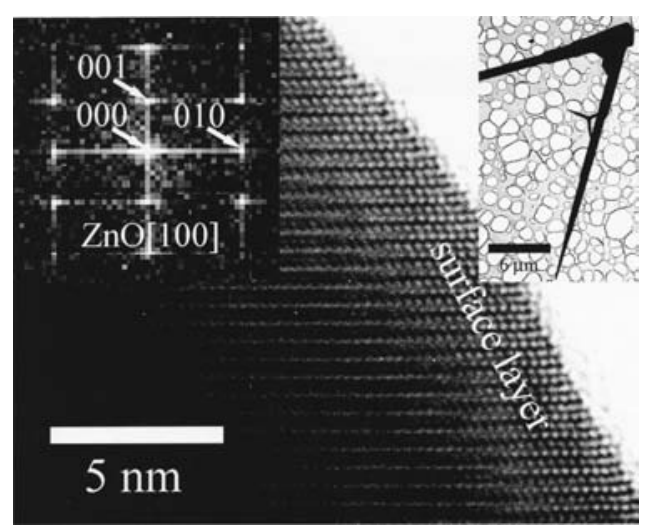

FIG. 2. HRTEM image of a $\mathrm{Mn}$ doped $\mathrm{ZnO}$ tetrapod. The left inset is the corresponding FFT diffractogram of the inner part. The right inset shows the

ing of $50 \mathrm{kOe}$. Inset shows the temperature dependencies of $H_{C}$ and $H_{E}$.
size of a whole pod.
Downloaded 08 Nov 2006 to 147.8.21.97. Redistribution subject to AlP license or copyright, see http://apl.aip.org/apl/copyright.jsp

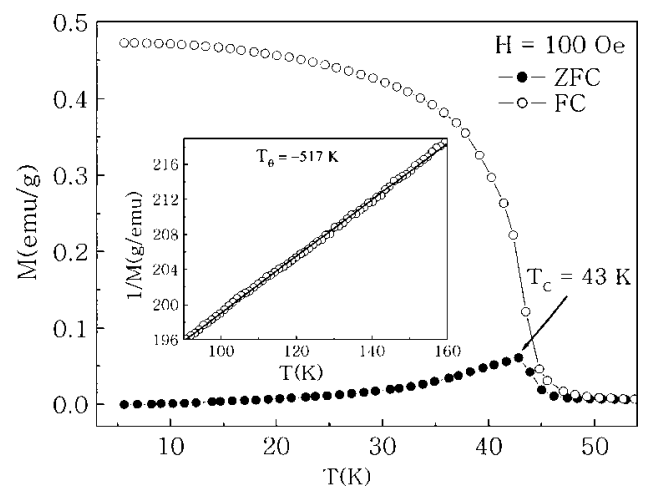

FIG. 3. ZFC-FC curves measured in $100 \mathrm{Oe}$ indicate $T_{C}=43 \mathrm{~K} . T_{\theta}$ $=-517 \mathrm{~K}$ can be obtained by extrapolating the $1 / M$ vs $T$ curve, as shown in the inset.

( $\mathrm{Zn}, \mathrm{Mn}) \mathrm{Mn}_{2} \mathrm{O}_{4}$ should be responsible to the magnetism of the $\mathrm{Mn}$ doped $\mathrm{ZnO}$ nanostructures.

Magnetic hysteresis loops were measured at various temperatures after the sample was cooled from $337 \mathrm{~K}$ in a field of $50 \mathrm{kOe}$. Large coercivity $H_{C}=9.2 \mathrm{kOe}$ was observed at $2 \mathrm{~K}$, which is much larger than previous reported values in the $\mathrm{Mn}$ doped $\mathrm{ZnO}$ materials. ${ }^{8} H_{C}=6.1 \mathrm{kOe}$ at $5 \mathrm{~K}$ was reported in the $\mathrm{Mn}_{3} \mathrm{O}_{4}$ particles of $200 \mathrm{~nm}$ in diameter. ${ }^{25}$ Theoretical calculations show that $H_{C}=4.6 \mathrm{kOe}$ at $4.2 \mathrm{~K}$ for bulk single crystals. ${ }^{23}$ In fact, our sample displays $H_{C}=5.5 \mathrm{kOe}$ at $5.5 \mathrm{~K}$, which is a reasonable value comparing with previous reports. Furthermore, the hysteresis loops of the Mn doped $\mathrm{ZnO}$ nanostructures have almost the same shape as those in the $\mathrm{Mn}_{3} \mathrm{O}_{4}$ particles. ${ }^{25}$ All phenomena observed indicate that ( $\mathrm{Zn}, \mathrm{Mn}) \mathrm{Mn}_{2} \mathrm{O}_{4}$ exists in the $\mathrm{Mn}$ doped $\mathrm{ZnO}$ nanostructures and dominates magnetic behaviors. The magnetization of $0.25 \mu_{B} / \mathrm{Mn}$ was found in a $50 \mathrm{kOe}$ field, which is about $1 / 2$ of previous reported value of $\mathrm{Mn}_{3} \mathrm{O}_{4}$ (e.g., $1.82 \mu_{B} /$ molecule). ${ }^{23}$ The reason for the reduction of the magnetization includes the formation of $(\mathrm{Zn}, \mathrm{Mn}) \mathrm{Mn}_{2} \mathrm{O}_{4},{ }^{26}$ the existence of antiferromagnetic manganese oxides, or $(\mathrm{Zn}, \mathrm{Mn}) \mathrm{O}^{5,8,14}$

Exchange bias was clearly observed below $22 \mathrm{~K}$ in the FC hysteresis loops. The temperature dependencies of the exchange bias field $\left(H_{E}\right)$ and coercivity $(H C)$ are shown in the inset of Fig. 4. To generate exchange bias, the system must have, at least, one fixed magnetic phase (usually an antiferromagnetic phase) that does not reverse during hysteresis loop measurements. ${ }^{27}$ There are two possible candidates for the fixed phase here: one is antiferromagnetic

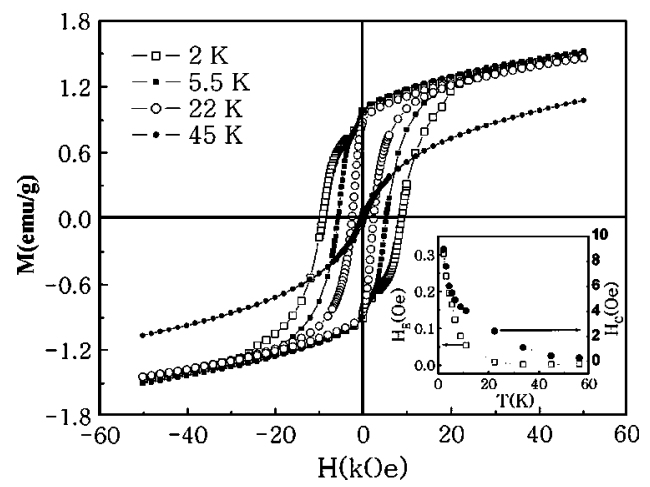

FIG. 4. Hysteresis loops measured at various temperatures after field cooling of $50 \mathrm{kOe}$. Inset shows the temperature dependencies of $H_{C}$ and $H_{E}$. 
$(\mathrm{Zn}, \mathrm{Mn}) \mathrm{O}^{5,12}$ the other is spin-glass-like manganese oxides $^{28,29}\left[(\mathrm{Zn}, \mathrm{Mn}) \mathrm{Mn}_{2} \mathrm{O}_{4}\right.$, or $\left.(\mathrm{Zn}, \mathrm{Mn}) \mathrm{O}\right]$. As shown in the inset of Fig. 4, exchange bias disappears above $22 \mathrm{~K}$, which is corresponding to the phase transition temperature of the fixed phase.

To summarize, it is found that the Mn-doped wurtzitetype $\mathrm{ZnO}$ nanostructures by diffusion are covered by the $\mathrm{Mn}$ rich layers, which might be $(\mathrm{Zn}, \mathrm{Mn}) \mathrm{Mn}_{2} \mathrm{O}_{4}$ suggested by the magnetic measurements. Exchange bias is clearly observed below $22 \mathrm{~K}$. Exchange bias is attributed to the exchange interaction between ferrimagnetic $(\mathrm{Zn}, \mathrm{Mn}) \mathrm{Mn}_{2} \mathrm{O}_{4}$ and antiferromagnetic $(\mathrm{Zn}, \mathrm{Mn}) \mathrm{O}$ or spin-glass-like phase in manganese oxides $\left[(\mathrm{Zn}, \mathrm{Mn}) \mathrm{Mn}_{2} \mathrm{O}_{4}\right.$ or $\left.(\mathrm{Zn}, \mathrm{Mn}) \mathrm{O}\right]$.

This work was supported by Research Grants Council of the Hong Kong Special Administration Region, China (Project Nos. HKUST6165/01P and HKUST6059/02E) and the University of Hong Kong University Research Committee Seed Funding Grant.

${ }^{1}$ S. A. Wolf, D. D. Awschalom, R. A. Buhrman, J. M. Daughton, S. von Molnar, M. L. Roukes, A. Y. Chtchelkanova, and D. M. Treger, Science 294, 1488 (2001).

${ }^{2}$ T. Dietl, H. Ohno, F. Matsukura, J. Cibert, and D. Ferrand, Science 287, 1019 (2000).

${ }^{3}$ Y. M. Kim, M. Yoon, I. W. Park, Y. J. Park, and J. H. Lyou, Solid State Commun. 129, 175 (2004).

${ }^{4}$ T. Fukumura, Z. W. Jin, A. Ohtomo, H. Koinuma, and M. Kawasaki, Appl. Phys. Lett. 75, 3366 (1999).

${ }^{5}$ T. Fukumura, Z. W. Jin, M. Kawasaki, T. Shono, T. Hasegawa, S. Koshihara, and H. Koinuma, Appl. Phys. Lett. 78, 958 (2001).

${ }^{6}$ Z. W. Jin, T. Fukumura, M. Kawasaki, K. Ando, H. Saito, T. Sekiguchi, Y. Z. Yoo, M. Murakami, Y. Matsumoto, T. Hasegawa, and H. Koinuma, Appl. Phys. Lett. 78, 3824 (2001).

${ }^{7}$ K. Ueda, H. Tabata, and T. Kawai, Appl. Phys. Lett. 79, 988 (2001).

${ }^{8}$ S. W. Jung, S. J. An, G. C. Yi, C. U. Jung, S. I. Lee, and S. Cho, Appl.
Phys. Lett. 80, 4561 (2002)

${ }^{9}$ J. H. Kim, J. B. Lee, H. Kim, W. K. Choo, Y. Ihm, and D. Kim, Ferroelectrics 273, 2449 (2002).

${ }^{10}$ D. P. Norton, S. J. Pearton, A. F. Hebard, N. Theodoropoulou, L. A. Boatner, and R. G. Wilson, Appl. Phys. Lett. 82, 239 (2003).

${ }^{11}$ X. M. Cheng and C. L. Chien, J. Appl. Phys. 93, 7876 (2003).

${ }^{12}$ S. W. Yoon, S. B. Cho, S. C. We, S. Yoon, B. J. Suh, H. K. Song, and Y. J. Shin, J. Appl. Phys. 93, 7879 (2003).

${ }^{13}$ K. Ip, R. M. Frazier, Y. W. Heo, D. P. Norton, C. R. Abernathy, S. J. Pearton, J. Kelly, R. Rairigh, A. F. Hebard, J. M. Zavada, and R. G. Wilson, J. Vac. Sci. Technol. B 21, 1476 (2003).

${ }^{14}$ S. J. Han, T. H. Jang, Y. B. Kim, B. G. Park, J. H. Park, and Y. H. Jeong, Appl. Phys. Lett. 83, 920 (2003).

${ }^{15}$ H. J. Zhou, D. M. Hofmann, A. Hofstaetter, and B. K. Meyer, J. Appl. Phys. 94, 1965 (2003).

${ }^{16}$ P. Sharma, A. Gupta, K. V. Rao, F. J. Owens, R. Sharma, R. Ahuja, J. M. O. Guillen, B. Johansson, and G. A. Gehring, Nat. Mater. 2, 673 (2003).

${ }^{17}$ Y. Q. Chang, D. B. Wang, X. H. Luo, X. Y. Xu, X. H. Chen, L. Li, C. P. Chen, R. M. Wang, J. Xu, and D. P. Yu, Appl. Phys. Lett. 83, 4020 (2003).

${ }^{18}$ N. A. Theodoropoulou, A. F. Hebard, D. P. Norton, J. D. Budai, L. A. Boatner, J. S. Lee, Z. G. Khim, Y. D. Park, M. E. Overberg, S. J. Pearton, and R. G. Wilson, Solid-State Electron. 47, 2231 (2003).

${ }^{19}$ V. A. L. Roy, A. B. Djurisic, H. Liu, X. X. Zhang, Y. H. Leung, M. H. Xie, J. Gao, H. F. Lui, and C. Surya, Appl. Phys. Lett. 84, 756 (2004).

${ }^{20}$ K. Sato and H. Katayama-Yoshida, Physica E (Amsterdam) 10, 251 (2001).

${ }^{21}$ K. Sato and H. Katayama-Yoshida, Physica B 308, 904 (2001).

${ }^{22}$ V. A. L. Roy, A. B. Djurisic, W. K. Chan, J. Gao, H. F. Lui, and C. Surya, Appl. Phys. Lett. 83, 141 (2003).

${ }^{23}$ K. Dwight and N. Menyuk, Phys. Rev. 119, 1470 (1960).

${ }^{24}$ G. Srinivasan and M. S. Seehra, Phys. Rev. B 28, 1 (1983).

${ }^{25}$ A. Buckelew, J. R. Galan-Mascaros, and K. R. Dunbar, Adv. Mater. (Weinheim, Ger.) 14, 1646 (2002).

${ }^{26}$ I. S. Jacobs and J. S. Kowel, Phys. Rev. 122, 412 (1961).

${ }^{27}$ R. K. Zheng, H. Liu, Y. Wang, and X. X. Zhang, Appl. Phys. Lett. 84, 702 (2004).

${ }^{28}$ R. H. Kodama, A. E. Berkowitz, E. J. McNiff, and S. Foner, Phys. Rev. Lett. 77, 394 (1996).

${ }^{29}$ B. Martinez, X. Obradors, L. Balcells, A. Rouanet, and C. Monty, Phys. Rev. Lett. 80, 181 (1998). 